\title{
Carbohydrate Metabolism in Agaricus bisporus (Lange) Sing.: Changes in Soluble Carbohydrates during Growth of Mycelium and Sporophore
}

\author{
By J. B. W. HAMMOND AND R. NICHOLS \\ Glasshouse Crops Research Institute, Littlehampton BNI6 $3 P U$, Sussex
}

(Received 5 June 1975; revised I $3_{3}$ October 1975)

\begin{abstract}
SUMMARY
Changes in the ethanol-soluble carbohydrate content of Agaricus bisporus mycelium and sporophores grown on semi-defined media and commercial compost were studied. The accumulation of mannitol in the sporophore during its growth was not accompanied by an increase in mycelial mannitol. The other major soluble carbohydrate of the sporophore, trehalose, decreased throughout the growth of the sporophore; a parallel decrease was observed in the mycelium. The main accumulation of mannitol was in the pileus and stipe of the sporophore and was accompanied by a decrease in the soluble protein content of these tissues. Before fruiting, glucose and sucrose were present in the mycelial samples in similar quantities to mannitol, but their levels decreased during fruiting. Small quantities of glucose were present in the sporophore. The results are discussed in relation to the possible functions of the soluble carbohydrates.
\end{abstract}

\section{INTRODUCTION}

Several workers have reported on the levels of soluble carbohydrates in the sporophore of Agaricus bisporus (Lange) Sing. and speculated on their functions (McConnell \& Esselen, 1947; Hughes, Lynch \& Somers, 1958; Rast, 1965; Holtz, I97I). Mannitol occurs in large quantities, while trehalose, the other major soluble carbohydrate, is present at lower levels.

In contrast, there is no information concerning the carbohydrate content of the mycelium of $A$. bisporus during sporophore production. This is an important omission, since the growth of the sporophore is dependent on substrate supplied by the mycelium (Bonner et al., I956), and thus a knowledge of mycelial metabolism is essential for an understanding of sporophore development.

We report here the results of a study of the soluble carbohydrate content in the sporophore and supporting mycelium, which was made as a basis for further metabolic investigations. The problem of producing normal sporophores from mycelium under laboratory conditions has not yet been resolved for $A$. bisporus. Consequently, mycelium was grown in a semi-defined, non-sterile medium in which sporophores could be produced, and mycelium was sampled by homogenizing the colonized medium.

\section{METHODS}

Small-scale culture. Agaricus bisporus ('Darlington's 62I', the strain used throughout this work) was grown on a small scale in polypropylene trays $(200 \times 70 \times 50 \mathrm{~mm})$. These were filled with a vermiculite- or peat-based medium (Table $\mathrm{r}$ ), covered and autoclaved. The 


\section{Table I. Composition of media used in small-scale cultures}

\begin{tabular}{lr}
\multicolumn{1}{c}{ Media } & $\begin{array}{r}\text { Weight used } \\
5 \text { trays } \\
(\mathrm{g})\end{array}$ \\
$\begin{array}{lr}\text { Peat/chalk mixture, } \mathrm{I}: \mathrm{I}(\mathrm{w} / \mathrm{w}) \\
\text { or vermiculite }\end{array}$ & $\mathrm{I} 000$ \\
Fine chopped straw & 250 \\
Soya flour & 53 \\
Glucose & 55 \\
Water & 40 \\
$\quad$ Peat-based mixture & \\
or vermiculite-based mixture &
\end{tabular}

sterile medium was inoculated with fresh commercial grain spawn under sterile conditions and incubated at $25^{\circ} \mathrm{C}$ (Smith and Hayes, 1972). After 3 to 4 weeks, when the medium was fully colonized with mycelium, those trays without visible contamination were covered with a Io mm layer of non-sterile vermiculite (equivalent to 'casing' in commercial terminology). Approximately $5 \mathrm{ml}$ of a filtered suspension of commercial casing soil was sprinkled on to the surface of the vermiculite to promote fruiting (Smith \& Hayes, 1972). The trays were transferred to $18{ }^{\circ} \mathrm{C}$ and watered when necessary; sporophores began to appear 3 to 4 weeks later.

Agar and liquid culture. Mycelium was grown on malt extract agar or in malt extract liquid medium at $25^{\circ} \mathrm{C}$.

Commercial culture. Agaricus bisporus was grown on compost under commercial conditions at the Glasshouse Crops Research Institute Mushroom Unit.

Carbohydrate extraction. Sporophores grown under commercial conditions were harvested at one of seven defined stages of development (Fig. I) (Hammond \& Nichols, 1975). The sporophores were taken from a single tray during one flush of a crop. They were dissected into stipe, gill and pileus immediately after harvesting, weighed and homogenized in $60 \%$ $(\mathrm{v} / \mathrm{v})$ aqueous ethanol. The homogenate was filtered and the residue weighed (residue dry weight) after drying at $80^{\circ} \mathrm{C}$. Sporophores from small-scale culture were extracted in the same way except that they were not dissected.

Because there was no way of separating intact mycelium from the medium, extracts from small-scale cultures were made by removing samples of colonized vermiculite from the 'casing' of peat-based media or the whole medium from vermiculite cultures, and homogenizing them in $60 \%$ aqueous ethanol. The suspension was filtered and the extract treated in the same way as that from the sporophores. Since the insoluble cell material could not be separated from the vermiculite, the soluble carbohydrate content of the extract has been expressed as a percentage of the weight of the total soluble material (t.s.m.). The ratio of extractable to non-extractable material varied between about 0.3 and $\mathrm{r} \cdot 0$ for mycelium grown in liquid culture, and between $\mathrm{I} \cdot \mathrm{O}$ and $\mathrm{I} \cdot 5$ for sporophores from compost.

Mycelium grown on agar was peeled from the surface of the agar, ensuring that none of the medium adhered to the sample; subsequent analysis demonstrated the absence of maltose, the major nutrient sugar, from the extracts, suggesting that there was no contamination from the medium. The mycelium was homogenized in $60 \%$ aqueous ethanol as described above. Mycelium grown in liquid culture was removed from the medium, washed twice and blotted with filter paper before extraction.

Carbohydrate analysis. The alcoholic extracts were taken to dryness in a rotary film evaporator, after addition of meso-inositol as an internal standard, and weighed. The weight of 

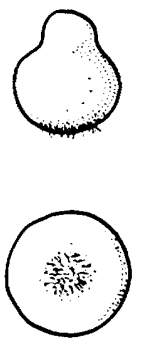

1
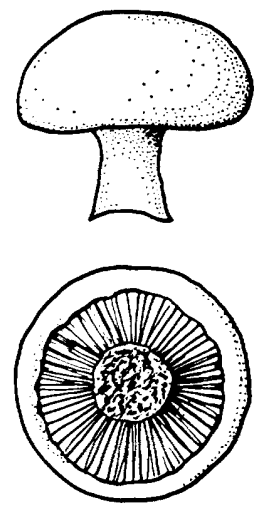

5
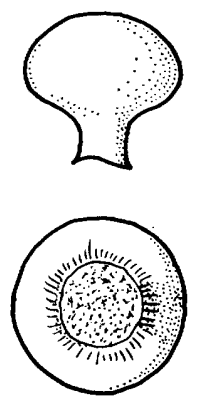

2
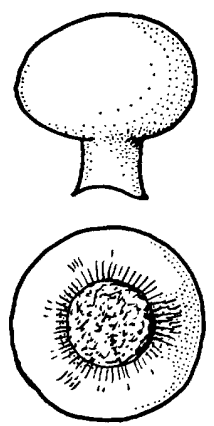

3

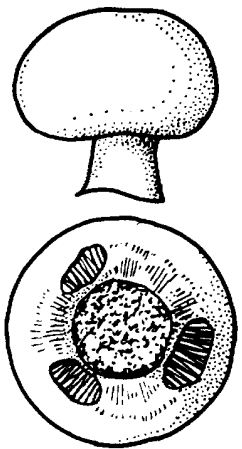

4
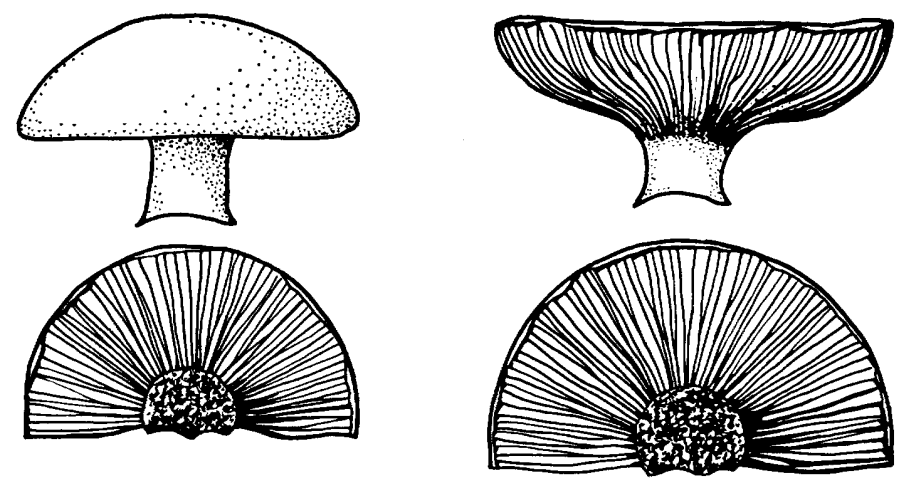

6

7

Fig. x. Appearance of sporophores at stages I to 7 .

the extract and the residue dry weight were added, to give the tissue dry weight. The extracts were treated to produce trimethylsilyl ethers by the method of Sweeley et al. (1963) and analysed by gas-liquid chromatography using a stationary phase of $\mathrm{E}_{54}$ silicone gum (Pye Unicam Ltd) coated ( $3 \%, \mathrm{w} / \mathrm{w})$ on silanized Celite (BDH; 80 to I 20 mesh). Full details of the carbohydrate extractions and analysis were given by Hammond \& Nichols (I975).

Soluble protein extraction and determination. Sporophores grown on compost were dissected into cold $\mathrm{O}^{\mathrm{I}} \mathrm{M}$-tris- $\mathrm{HCl}$ buffer, $\mathrm{pH} \mathrm{8.6,} \mathrm{and} \mathrm{frozen.} \mathrm{After} \mathrm{thawing,} \mathrm{the} \mathrm{material}$ was homogenized and made up to a standard volume with cold distilled water. Portions of the suspension were taken for dry weight determination and the homogenate was filtered. Protein content of the filtrate was determined by the method of Lowry et al. (I95I) using bovine serum albumin standards.

\section{RES ULTS}

Validity of determinations of mycelial carbohydrates

The method used for extraction and determination of mycelial carbohydrates was chosen because of the difficulty of producing sporophores from $A$. bisporus mycelium in axenic, defined culture. The results obtained in three experiments were consistent both in trends and levels of carbohydrates observed (Fig. 2; Table 2). The carbohydrates detected in the 


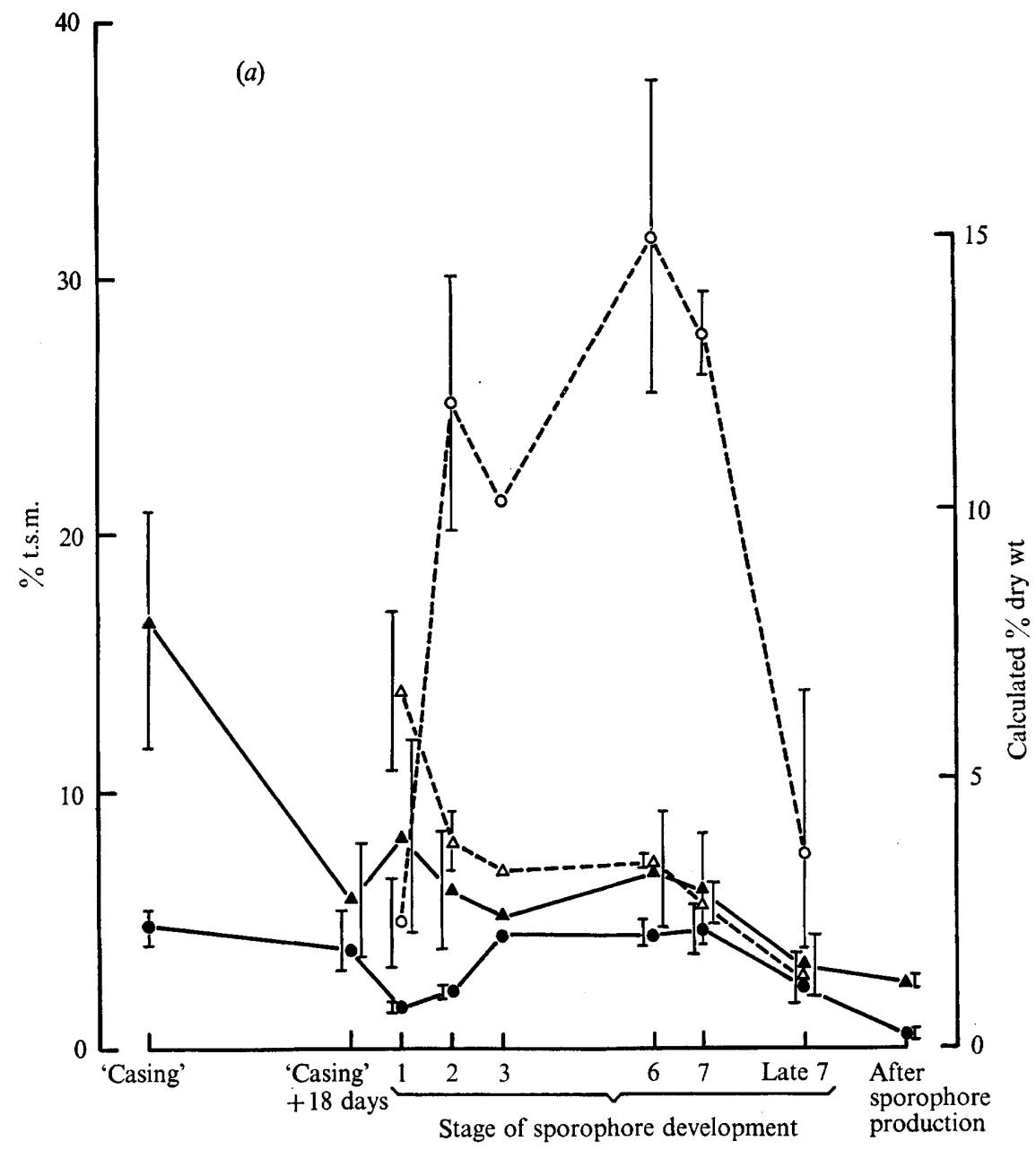

Fig. 2. Soluble carbohydrate changes in mycelium (solid symbols) and sporophores (open symbols) grown in small-scale culture. (a) Mannitol, $(\boldsymbol{\bullet}, \bigcirc)$ and trehalose $(\boldsymbol{\Lambda}, \Delta) ;(b)$ glucose $(\boldsymbol{\nabla}, \nabla)$ and sucrose $(\square, \square)$. Results are from a typical experiment; bars indicate range of mean, one to three samples per point. The percentage of total tissue dry weight was calculated from an estimated soluble to non-soluble ratio of 0.9 .

extracts were those normally found in A. bisporus sporophores and vegetative mycelium, and they were present in similar quantities to those in vegetative mycelium; thus it appears that contamination from the growth medium was small.

The justification for using t.s.m. to express the carbohydrate content of mycelial extracts was based on a comparison of t.s.m. and total dry matter values determined for mycelium grown on liquid and agar cultures. Since the correlation between the two methods was good (Table 3), it was concluded that t.s.m. could reasonably be used for small-scale cultures.

The changes in trehalose levels in mycelial samples were similar to those observed in the sporophores produced by the mycelium (Fig. $2 a$; Table 2). The carbohydrate changes observed in the culture-grown sporophores resembled those in compost-grown sporophores (Figs. 2 and 3 ). 


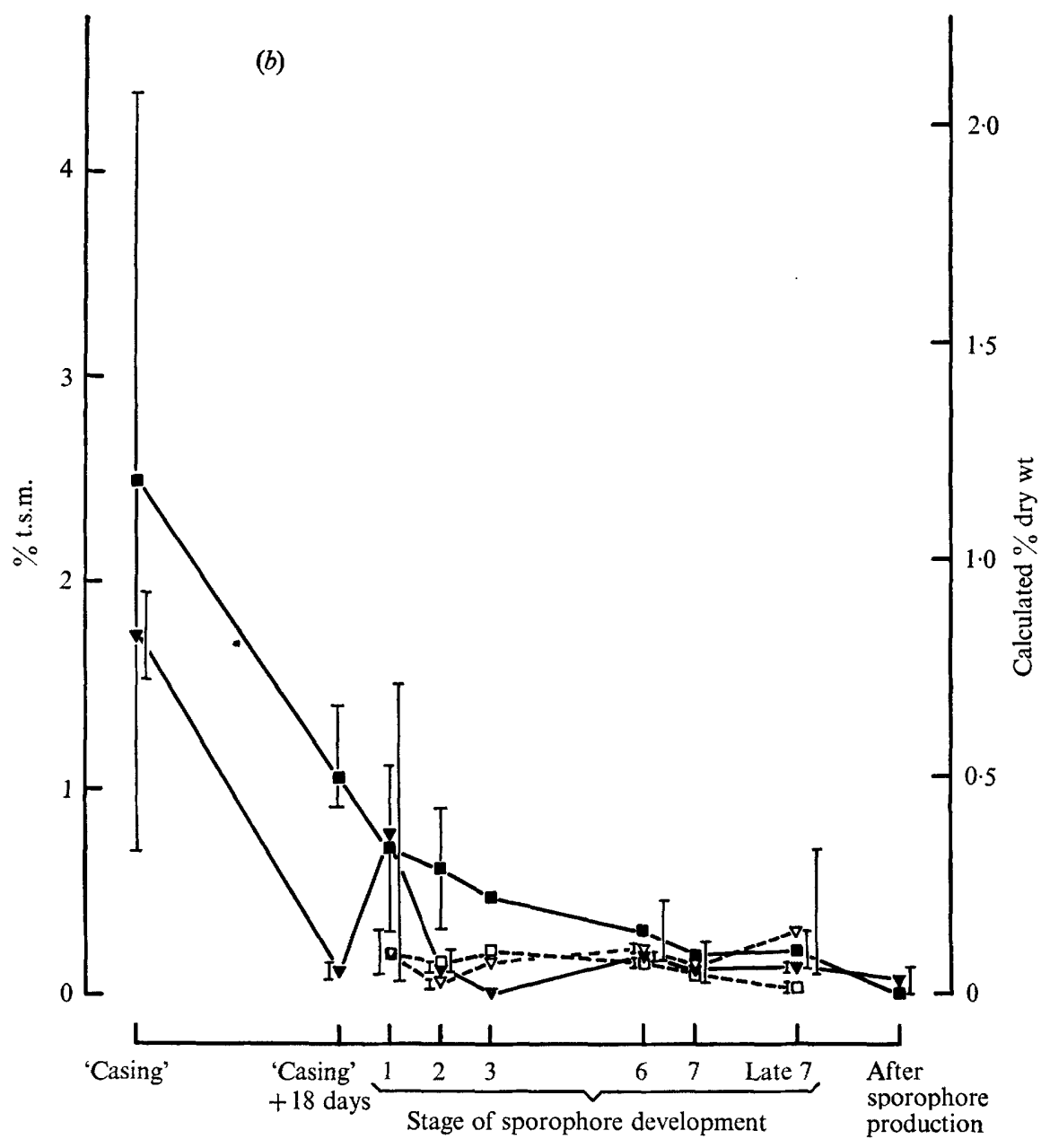

Fig. $2 b$. For legend see facing page.

Soluble carbohydrates in sporophores and parent mycelium

Only four carbohydrates, mannitol, trehalose, glucose and sucrose, were consistently detected in the mycelial extracts. Little difference was seen between samples from peatand vermiculite-based media, and so the results were combined. The results of one experiment are shown in Fig. 2; selected data from this and two other experiments are shown in Table 2.

At 'casing' (i.e. 3 to 4 weeks after inoculation), the mycelium contained approximately I $6 \%$ t.s.m. trehalose but only $5 \%$ t.s.m. mannitol (Fig. $2 a$ ). The mycelial trehalose level declined throughout the experimental period to about $2.5 \%$ t.s.m. after sporophore growth was over. Mannitol declined to about half its initial value during early sporophore growth, followed by recovery to the previous level, but finally fell as the sporophore reached the later stages of development.

The sporophores differed greatly from the mycelium in their mannitol content. Mannitol accumulated in the sporophores throughout development until at stage 6 it composed approximately $32 \%$ t.s.m., approximately eight times greater than that in the mycelium. 
Table 2. Mannitol and trehalose content of mycelium and sporophores grown in small-scale culture

\begin{tabular}{|c|c|c|c|c|c|c|}
\hline \multicolumn{7}{|c|}{ Mannitol (\% t.s.m.) } \\
\hline & \multicolumn{2}{|c|}{ Expt I } & \multicolumn{2}{|c|}{ Expt 2} & \multicolumn{2}{|c|}{ Expt 3} \\
\hline & Mycelium & Sporophore & Mycelium & Sporophore & Mycelium & Sporophore \\
\hline 'Casing' & $4 \cdot 3$ & - & $6 \cdot 6$ & - & $4 \cdot 8$ & - \\
\hline 'Casing' +18 days & $7 \cdot 4$ & - & - & - & $3 \cdot 9$ & - \\
\hline Stage I & $4 \cdot 8$ & $9 \cdot 5$ & $I \cdot 3$ & 13.5 & $I \cdot 6$ & 4.9 \\
\hline Stage 2 & $5 \cdot 4$ & $3 I \cdot I$ & $4 \cdot 7$ & $2 \mathrm{I} \cdot 7$ & $2 \cdot 2$ & $25 \cdot 2$ \\
\hline Stage 7 & $3 \cdot 4$ & $42 \cdot I$ & $2 \cdot 4$ & $27 \cdot 3$ & $4 \cdot 6$ & $28 \cdot 0$ \\
\hline \multicolumn{7}{|c|}{ Trehalose ( $\%$ t.s.m.) } \\
\hline 'Casing' & $22 \cdot 8$ & - & I6.3 & 一 & $16 \cdot 5$ & - \\
\hline 'Casing'+ I8 days & Is $\quad 15.6$ & - & - & - & $5 \cdot 8$ & - \\
\hline Stage I & $14 \cdot 2$ & 19.5 & $3 \cdot I$ & $9 \cdot 4$ & $8 \cdot 3$ & 13.9 \\
\hline Stage 2 & $6 \cdot 7$ & $9 \cdot 3$ & $4 \cdot 7$ & II 4 & $6 \cdot I$ & $8 \cdot 0$ \\
\hline Stage 7 & $2 \cdot 9$ & $3 \cdot 5$ & $4 \cdot 5$ & $9 \cdot 8$ & $6 \cdot 2$ & $5 \cdot 6$ \\
\hline
\end{tabular}

Table 3. Range of values for mannitol and trehalose levels in mycelium and hyphal aggregations grown on agar and liquid media, compared with values from small-scale cultures

The correlation coefficient between $\%$ t.s.m. and \% dry wt for combined values for mannitol is 0.96 and for trehalose $0.85(P=0.001)$. Row values are derived from separate cultures.

(A) Vegetative mycelium

Medium

Liquid malt extract

Malt extract agar

Small-scale culture (values at 'casing')

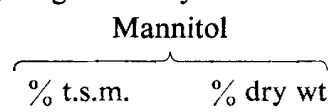

\section{$9 \cdot 5$}

$8 \cdot 4$

$3 \cdot 6$

$8 \cdot 6$

I $2 \cdot$ I

$6 \cdot 6$

$4 \cdot 3$

$4 \cdot 8$

$5 \cdot \mathrm{I}$ $\overbrace{\% \text { t.s.m. }}^{\text {Trehalose }} \overbrace{\% \text { dry wt }}^{\% \text { d }}$

$25.8 \quad 8.6$

$16.4 \quad 4.0$

$23 \cdot 2 \quad 8 \cdot 7$

$20.3 \quad 9 \cdot 1$

$25 \cdot 8 \quad 9 \cdot 9$

16.3

$22 \cdot 8$

I6.6

$14 \cdot 2$

(B) Mycelium bearing hyphal aggregations

Liquid malt extract

Mycelium

Aggregation

Malt extract agar

Mycelium

Aggregation

Mycelium

Aggregation

$\begin{array}{rr}3 \cdot 2 & 1 \cdot 5 \\ 9 \cdot 2 & 2 \cdot 7 \\ & \\ 18 \cdot 2 & 4 \cdot 3 \\ 30 \cdot 4 & 10 \cdot 5 \\ 16 \cdot 0 & 4 \cdot 5 \\ 27 \cdot 9 & 10 \cdot 2\end{array}$

$\begin{array}{rr}25 \cdot \text { I } & \text { I I } \cdot 9 \\ 30 \cdot 8 & 9 \cdot 0 \\ & \\ \text { I } 7 \cdot 8 & 4 \cdot 2 \\ 10 \cdot 7 & 3 \cdot 7 \\ 14 \cdot 9 & 4 \cdot 2 \\ 9 \cdot 8 & 3 \cdot 6\end{array}$

When the sporophore reached the later stages of development the mannitol content fell sharply to about $8 \%$ t.s.m. There was no rise in other soluble carbohydrates accompanying the fall in mannitol in either the sporophore or mycelium. The level of trehalose in the sporophore followed that observed in the mycelium fairly closely. Thus soluble carbohydrates formed a much greater proportion of the extracted material in the case of the sporophore than in its parent mycelium; this difference was due almost entirely to mannitol. An increase in mannitol content over that observed in the mycelium was seen in hyphal 

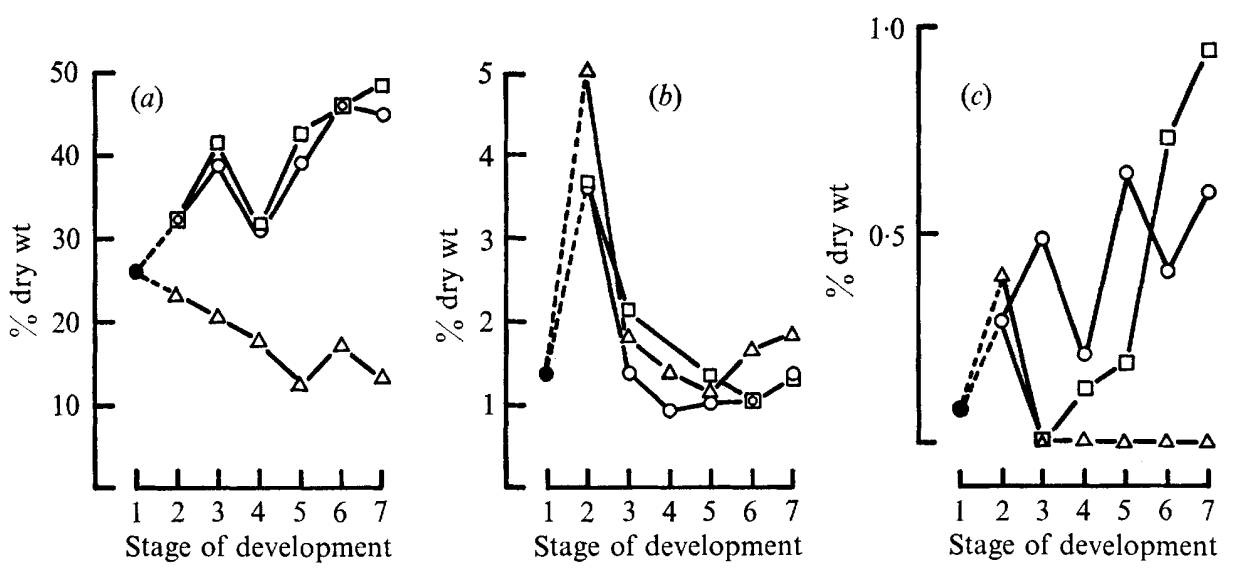

Fig. 3. Soluble carbohydrate changes in sporophores grown on compost. (a) Mannitol; (b) trehalose; (c) glucose. 0 , Whole stage $I ; \square$, stipe; $O$, pileus; $\triangle$, gill. Results are from one experiment, values from bulked samples.

aggregations growing on liquid and agar media (Table 3 B). Such aggregations are similar in appearance to normal sporophore primordia but do not generally undergo differentiation.

Sucrose levels in mycelial extracts decreased rapidly from about $2.5 \%$ t.s.m. at 'casing' to below $0.5 \%$ t.s.m. in mycelium and sporophore during fruiting (Fig. 2 b). Glucose levels in mycelial extracts were about $\mathrm{I} \cdot 7 \%$ t.s.m. at 'casing' and decreased in both sporophore and mycelium during the period of fruiting. The initial values for glucose and sucrose observed in the other experiments were between approximately $\mathrm{I}$ and $4 \%$ t.s.m.

\section{Soluble carbohydrate changes in compost-grown sporophores}

The changes observed in carbohydrates of compost-grown sporophores were similar to those described above. Higher levels of mannitol were found in compost-grown sporophores. Only a single fruiting cycle ('flush' or 'break') was observed in the cultures and the sporophores were smaller than those normally produced under commercial conditions, in which four to five flushes are not unusual; these effects were probably due to the limited amount of substrate present. The results of one of two similar experiments are shown in Fig. 3. The results obtained in the other experiment showed the same qualitative and quantitative trends in carbohydrate concentration.

The pattern of mannitol accumulation in the different tissues resembled that described by Rast (I965). Mannitol accumulated in the pileus and stipe during growth, rising from approximately 30 to $50 \%$ dry wt between stages 2 and 7 ; there was little difference between stipe and pileus mannitol levels throughout development (Fig. 3a). The level of mannitol in the gill decreased from 23 to $14 \%$ dry wt over the same period. Thus there was a distinct difference in mannitol content between the gills and the rest of the sporophore.

Trehalose levels were similar in all sporophore tissues and fell during development from approximately $5 \%$ dry wt at stage 2 to between I and $2 \%$ at stage 7 (Fig. $3 b$ ). The increase in trehalose between stages $I$ and 2 was observed in both experiments, but was not seen in the sporophores taken from small-scale culture; this difference may be connected with the different fruiting behaviour (single flush, smaller sporophores) seen in the small-scale culture. Only low levels of glucose $(<\mathrm{I} \%$ dry wt) were found (Fig. $3 c$ ); more was present in the stipe and pileus than in the gill tissue. The amount in the stipe and pileus appeared to 
Table 4. Concentration of mannitol and trehalose in sporophore tissues during growth Means of five samples from two experiments, \pm S.E.M.

\begin{tabular}{|c|c|c|c|c|c|}
\hline \multirow[b]{2}{*}{ Stage } & \multirow{2}{*}{$\begin{array}{l}\text { Section } \\
\text { of } \\
\text { sporophore }\end{array}$} & \multicolumn{2}{|c|}{ Mannitol } & \multicolumn{2}{|c|}{ Trehalose } \\
\hline & & $\%$ dry wt & $\mathrm{mmol} \mathrm{1}^{-1}$ & $\%$ dry wt & $\mathrm{mmol} \mathrm{l}^{-1}$ \\
\hline I & $\begin{array}{l}\text { Pileus } \\
\text { Stipe } \\
\text { Gill }\end{array}$ & $\begin{array}{l}34 \cdot 4 \pm 3 \cdot 4 \\
33 \cdot 3 \pm 4 \cdot 8 \\
I 6 \cdot I \pm I \cdot 0\end{array}$ & $\begin{array}{r}175 \pm 14 \\
127 \pm 20 \\
92 \pm 6\end{array}$ & $\begin{array}{l}2 \cdot 3 \pm 0.6 \\
2 \cdot 9 \pm 0.8 \\
2 \cdot 7 \pm 0.8\end{array}$ & $\begin{array}{l}5 \cdot 5 \pm I \cdot 7 \\
6 \cdot 6 \pm 2 \cdot 6 \\
8 \cdot 6 \pm 2 \cdot 9\end{array}$ \\
\hline 5 & $\begin{array}{l}\text { Pileus } \\
\text { Stipe } \\
\text { Gill }\end{array}$ & $\begin{array}{l}36 \cdot 2 \pm 5 \cdot 9 \\
44 \cdot 9 \pm 3 \cdot 3 \\
I 7 \cdot 7 \pm I \cdot 4\end{array}$ & $\begin{array}{r}131 \pm 18 \\
169 \pm 24 \\
92 \pm 5\end{array}$ & $\begin{array}{l}0.9 \pm 0.1 \\
2 \cdot 0 \pm 0.2 \\
I \cdot 3 \pm 0.1\end{array}$ & $\begin{array}{l}I \cdot 7 \pm 0.2 \\
4 \cdot 0 \pm 0.7 \\
3.4 \pm 0.2\end{array}$ \\
\hline 7 & $\begin{array}{l}\text { Pileus } \\
\text { Stipe } \\
\text { Gill }\end{array}$ & $\begin{array}{l}49 \cdot 4 \pm 3 \cdot 8 \\
52 \cdot 3 \pm 9 \cdot 0 \\
I 2 \cdot I \pm 2 \cdot I\end{array}$ & $\begin{array}{r}195 \pm 22 \\
164 \pm 33 \\
63 \pm 13\end{array}$ & $\begin{array}{l}I \cdot 0 \pm 0 . I \\
I \cdot 7 \pm 0.3 \\
I \cdot 4 \pm 0.2\end{array}$ & $\begin{array}{l}2 \cdot 1 \pm 0.3 \\
2 \cdot 8 \pm 0.6 \\
3.9 \pm 0.6\end{array}$ \\
\hline
\end{tabular}

increase during development, whereas that in the gill decreased to near the limits of detection. No other soluble carbohydrates were detected consistently.

\section{Concentration of mannitol and trehalose in sporophores}

Almost all of the water in sporophores at stages later than stage $\mathrm{I}$ is intracellular (B. Acock, personal communication). Values for cellular concentrations of carbohydrates, assuming there was no compartmentation, were derived from the carbohydrate content and the amount of water present in the fresh tissue. Considerable variation was evident between samples (Table 4). It seems likely that this was a result of differences between populations, since the trends in mannitol and trehalose levels were similar to those recorded in other experiments. The concentration of mannitol was high in the three stages sampled, varying between 127 and $195 \mathrm{mmol} \mathrm{l}^{-1}$ in the stipe and pileus, and between 92 and $63 \mathrm{mmol} \mathrm{l}^{-1}$ in the gills (Table 4).

\section{Soluble protein content of sporophores}

The protein content of the sporophore tissues was measured to find out whether a change in protein level could be associated with the increase in mannitol in the stipe and pileus reported by Rast (1965). There was some evidence that this might be the case from the observations of Vogel \& Weaver (1972), who described a migration of cytoplasm towards the gills.

A protein content of approximately $\mathrm{I} 3$ to $25 \%$ dry wt was observed. These values are in general agreement with those quoted elsewhere (Diem \& Lentner, 1970; Delmas, 1973). An increase from 8.2 to $15.8 \%$ of sporophore dry weight between stages I and 7 was observed in one experiment, and a decrease from 20.6 to $16.6 \%$ in another. These differences may have been due to variation in material.

The protein extracted showed an overall decrease of 6 to $7 \%$ dry wt in the stipe and pileus during sporophore development (Fig. 4). The soluble protein content appeared to be slightly higher in the pileus than in the stipe. The protein level in gill tissue was slightly higher than that in the rest of the sporophore at stage 2 , and increased as the sporophore matured until at stage 7 it was double that observed in the stipe. 


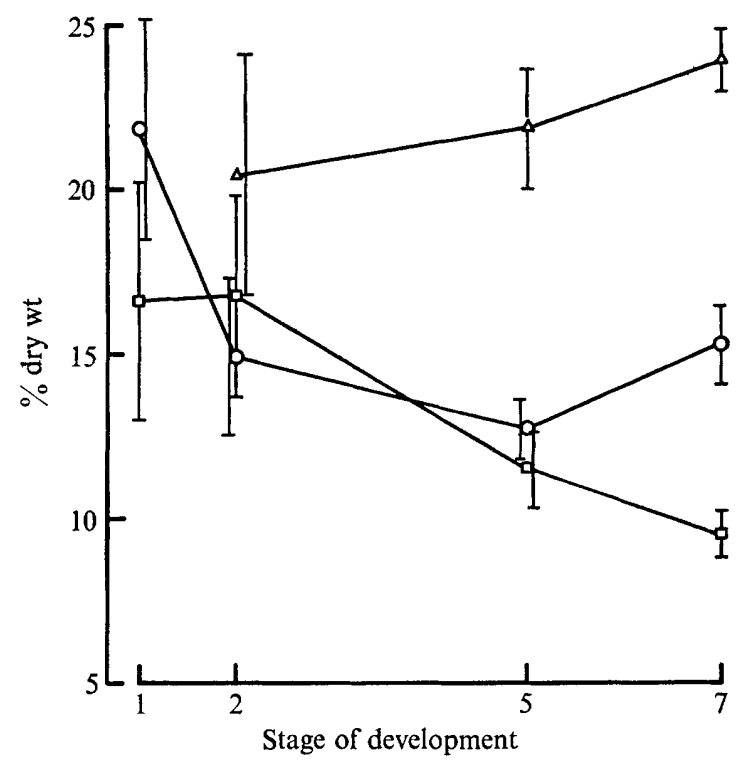

Fig. 4. Changes in soluble protein content during growth of sporophores grown on compost.

$\square$, Stipe; $O$, pileus; $\Delta$, gill. Results are from three experiments and bars show the S.E.M.

\section{DISCUSSION}

Our observations on the accumulation of mannitol during sporophore growth confirm and extend the findings of Rast (1965). Soluble carbohydrate analyses of fruiting A. bisporus mycelium have not been reported previously. Our results show that the mycelium contained much the same soluble carbohydrates as the sporophore, but the mannitol content was lower than that of the sporophore. Trehalose levels in the mycelium were similar to those in the sporophore, and both showed a similar fall in trehalose level during sporophore growth. Sucrose appeared to be!characteristic of the mycelium samples; only traces were found in the sporophores (Fig. $2 b$ ). Glucose levels were similar in mycelium and sporophore.

Mannitol synthesis in the $A$. bisporus sporophore has been shown to involve the reoxidation of NADPH formed in the operation in the hexose monophosphate pathway (HMP) (Dütsch \& Rast, 1972) by reduction of fructose to mannitol in the mannitol dehydrogenase $(\mathrm{MDH})$ reaction. The HMP appears to be the major oxidative pathway in the A. bisporus sporophore (Le Roux, I967; Graham, I97I), and Dütsch \& Rast (1972) speculated that the rate of oxidation of NADPH by mannitol formation may be a means of controlling the rate of glucose oxidation by the HMP.

The high concentration of mannitol in the cell solution (Table 4), and the virtual absence of free fructose, in relation to the kinetic parameters of $\mathrm{MDH}\left(K_{m}\right.$ mannitol $4.6 \times 1 \mathrm{O}^{-4} \mathrm{M}$, $K_{m}$ fructose $\mathrm{I} \cdot 4 \times \mathrm{IO}^{-3} \mathrm{M}$; Edmundowicz \& Wriston, I963), show that there could be impairment of the efficiency of the enzyme by binding of mannitol to most of the MDH present. If there is no compartmentation of $\mathrm{MDH}$ and mannitol, and binding does occur, then it seems unlikely that this reaction could be a major controller of HMP rate. It is possible, however, that such an effect could place a restriction on the rate of mannitol formation when higher mannitol concentrations are reached. 
The difference in mannitol level between the gill and the remainder of the sporophore (Fig. $3 a$ ) may be a reflexion of the different functions which these tissues fulfil, rather than being due to transport from the mycelium as suggested by Rast (1965). The gill tissue is concerned with spore production, and the high levels of biosynthesis which are associated with this could utilize NADPH which would otherwise be used in mannitol formation. The stipe and pileus tissue act mainly as a support for the gill tissue and may be expected to show lower levels of reductive biosynthesis. Mannitol may fulfil an osmotic function in the stipe and pileus, providing turgor pressure for support of the fruit body and the considerable extension growth which occurs (Bonner et al., 1956). The greater metabolic activity of the gill tissue is reflected in the migration of cytoplasm and mitochondria into the gills from the rest of the sporophore during development (Vogel \& Weaver, 1972). Our results (Fig. 4) showing the increase of soluble protein in the gill tissue and decrease in the stipe and pileus during growth, support this observation. The increase in stipe and pileus glucose and decrease in gill glucose during sporophore growth may be a reflexion of the relative metabolic activities of the tissues, the lower levels of glucose being observed in areas of greater activity.

The relatively low levels of mannitol observed in the mycelium suggest that mannitol is not transported to the sporophore; any such movement would take place against a steep concentration gradient. It is possible that some movement of mannitol occurs up to about stage I of sporophore growth, since mycelial mannitol levels fell temporarily at this point (Fig. 2a). However, an alternative interpretation of this drop in mannitol content is that it is due to increased biosynthetic activity of the mycelium during sporophore initiation and early growth.

The low level of mannitol seen in the mycelium throughout the experiment could be due to greater use of NADPH in biosynthesis, an alternative method of oxidation of NADPH, or to reduced HMP activity. Little information is available on the oxidative metabolism of the mushroom mycelium, but in other fungi changes in HMP activity have been associated with morphogenesis. Recently, Schwalb (1974) showed a relative increase in glucose-6phosphate dehydrogenase activity in fruiting of Schizophyllum commune. Also, increases in HMP enzymes have been observed in sclerotium formation in Sclerotinia sclerotiorum (Wong \& Willetts, 1974), which is also a process involving the production of dense hyphal aggregations. A similar increase in HMP activity could occur during primordium formation in $A$. bisporus.

The observed fall in sporophore mannitol at the end of development (Fig. $2 a$ ) may be due to a reversal of the normal substrate flow from the mycelium, and conversion of mannitol to an undetected material in the mycelium or to utilization by the sporophore. It seems most likely that much of the mannitol is lost through sporophore respiration, perhaps after a reduction in flow of substrate from the mycelium, since no increases were observed in any other carbohydrates. The use of mannitol as a storage material has been suggested previously (Cochrane, 1958), and Hammond \& Nichols (1975) found that mannitol appeared to act as a major respiratory substrate after harvest.

In contrast to mannitol, trehalose levels in mycelium and sporophore appeared to be similar. This suggests that it is mobile throughout the culture. It has been suggested previously that trehalose is translocated in fungi (Cochrane, 1958). The fall in the combined trehalose levels in the sporophore and mycelium from small-scale culture are almost certainly not enough to accord with its use as a major energy source in sporophore growth. It is possible that trehalose levels are maintained by synthesis from insoluble carbohydrate reserves in the mycelium. Fruiting in Schizophyllum commune and Coprinus lagopus are reported to be accompanied by breakdown of insoluble reserves (Wessels, 1965; Madelin, 
1960). In this case the fall in trehalose could reflect a fall in reserve material. Trehalose levels fell rapidly between casing and fruiting and more slowly during fruiting, although the latter phase must involve a greater expenditure of substrates. This inconsistency may be due to a change in the relationship between trehalose and the postulated reserves. The low level of trehalose found in stage I sporophores grown on compost (Fig. $3 b$ ) was consistent between experiments, but did not agree with the results obtained from small-scale cultures (Table 2). Sporophores grown on compost were not taken from the first flushes of crops. The between-flush levels of trehalose may be low, with new trehalose synthesis only beginning when the new flush has started to develop. In the single flush which was observed in the small-scale culture, trehalose levels could be quite high since there had been no drain on reserves by previous production of sporophores.

Further work aimed at clarifying the metabolic processes underlying the observations described here is in progress.

The authors thank Mr J. F. Smith of the Microbiology Department, Glasshouse Crops Research Institute, for his advice on the small-scale cultures and Dr D. A. W. Wood, of the same department, for providing cultures on agar and liquid media for carbohydrate analysis.

\section{REFERENCES}

Bonner, J. T., Kent Kane, K. \& LeVEy, R. H. (1956). Studies on the mechanics of growth in the common mushroom Agaricus campestris. Mycologia 48, I3-19.

Cochrane, V. W. (1958). Carbon metabolism. II. The metabolism of carbohydrates and related compounds. In Physiology of the Fungi, pp. 108-122. New York: John Wiley.

Delmas, J. (1973). Valeur alimentaire du champignon de couche Agaricus bisporus cultivé. Bulletin de la Fédération Nationale des Syndicats Agricoles des Cultivateurs de Champignons 13, 537-557.

Diem, K. \& Lentner, C. (1970). In Geigy Scientific Tables, p. 504. Macclesfield: Geigy Pharmaceuticals.

DüTSCH, G. A. \& RAST, D. (I972). Biochemische Beziehung zwischen Mannitbildung und Hexosemonophosphatzyklus in Agaricus bisporus. Phytochemistry II, 2677-268I.

Edmundowicz, J. M. \& WRISTon, J. C., JR. (1963). Mannitol dehydrogenase from Agaricus campestris. Journal of Biological Chemistry 238, 3539-354I.

Graham, D. G. (1971). Protein and energy metabolism of mitochondria of the common meadow mushroom (Agaricus bisporus) in extracellular culture. Ph.D. thesis, Duke University, U.S.A.

Hammond, J. B. W. \& Nichols, R. (I975). Changes in respiration and soluble carbohydrates during the post-harvest storage of mushrooms (Agaricus bisporus). Journal of the Science of Food and Agriculture 26, 835-842.

Holtz, R. B. (197I). Qualitative and quantitative analyses of free neutral carbohydrates in mushroom tissue by gas-liquid chromatography and mass spectrometry. Journal of Agricultural and Food Chemistry 19, I 272-I 273.

Hughes, H. D., LyNCH, D. L. \& Somers, G. F. (1958). Chromatographic identification of the amino acids and carbohydrates in the cultivated mushroom, Agaricus campestris L. ex Fries. Journal of Agricultural and Food Chemistry 6, 850-853.

Le Roux, P. (1967). Métabolisme carboné et azoté du champignon cultivé. Mushroom Science 6, 179-190.

Lowry, O. H., Rosebrough, N. J., FARr, A. L. \& Randall, R. J. (I95I). Protein measurement with the Folin phenol reagent. Journal of Biological Chemistry $\mathbf{1 9 3}, 265-275$.

Madelin, M. F. (1960). Visible changes in the vegetative mycelium of Coprinus lagopus Fr. at the time of fruiting. Transactions of the British Mycological Society 43, 105-I I0.

MCConnell, J. E. W. \& Esselen, W. B. (I947). Carbohydrates in cultivated mushrooms (Agaricus campestris). Food Research 12, I I 8-I 2 I.

RAST, D. (1965). Zur stoffwechselphysiologischen Bedeutung von Mannit und Trehalose in Agaricus bisporus (eine gaschromatographische Studie). Planta 64, 8I-93.

Schwalb, M. N. (1974). Changes in activity of enzymes metabolising glucose-6-phosphate during development of the Basidiomycete Schizophyllum commune. Developmental Biology 40, 84-89.

SMith, J. F. \& HAYEs, W. A. (1972). Use of autoclaved substrates in nutritional investigations on the cultivated mushroom. Mushroom Science 8. 355-36r. 
Sweeley, C. C., Bentley, R., Makita, M. \& Wells, W. W. (1963). Gas-liquid chromatography of trimethylsilyl derivatives of sugars and related substances. Journal of the American Chemical Soceity 85, 2497-2507.

VOGEL, F. S. \& WeAVER, R. F. (1972). Concerning the induction of dormancy in spores of Agaricus bisporus. Experimental Cell Research 75, 95-104.

WesseLs, J. G. H. (1965). Morphogenesis and biochemical processes in Schizophyllum commune Fr. Wentia I3, I-II3.

WoNG, A.-L. \& WiLlETTS, H. J. (1974). Polyacrylamide-gel electrophoresis of enzymes during morphogenesis of sclerotia of Sclerotinia sclerotiorum. Journal of General Microbiology 81, 10I-109. 